\title{
A Novel Cellular Autoaggregative Developmentally CRP Regulated Behaviour Generates Massively Chondrule-Like Formations over Surface of Old Escherichia coli K-12 Macrocolony Biofilms
}

\author{
José María Gómez Gómez ${ }^{1,2 *}$, Ricardo Amils,3 \\ ${ }^{1}$ Centro de Biología Molecular Severo Ochoa C/Nicolás Cabrera № 1; Departamento de Virología y \\ Microbiología Laboratorio 104 Campus of Universidad Autónoma de Madrid, Madrid, Spain \\ ${ }^{2}$ OAS-BioAstronomy Group Observatorio Astronómico de Segurilla (OAS) 45621 Camino de Valparaiso S/N \\ Segurilla, Toledo, Spain \\ ${ }^{3}$ Centro de Astrobiología (CSIC-INTA) (Associated with NASA Astrobiology Institute) Ctra Ajalvir km 428850 \\ Torrejón de Ardoz Madrid, Madrid, Spain \\ Email: $\underline{\text { chemaseg@yahoo.es }}$
}

Received 1 June 2014; revised 18 July 2014; accepted 1 August 2014

Copyright (C) 2014 by authors and Scientific Research Publishing Inc.

This work is licensed under the Creative Commons Attribution International License (CC BY).

http://creativecommons.org/licenses/by/4.0/

(c) (i) Open Access

\section{Abstract}

How Escherichia coli bacteria develop a particular colonial, 3-D biofilm morphological pattern is still a poorly understood process. Recently, we reported a new $E$. coli K-12 morphotype exhibited by old macrocolonies described as volcano-like. The formative developmental process of this morphotype has been presented as a suitable experimental model for the study of 3D patterning in macrocolony biofilms. Here, we report the optical microscopy observations and genetic analysis that have unveiled the existence of a novel autoaggregative behaviour which generates massive lumpiness over the surface of the volcano-like macrocolonies. These lumpy formations are generated by the autoaggregation and strong interaction of tightly packed bacterial cells in structures with a chondrule-like appearance which give the colony's surface its characteristic microscopic lumpy phenotype. Furthermore, they exhibit different levels of maturation from the edge to the center of the colony. Hence, its generation appears to follow a spatiotemporal program of development during the macrocolony's morphogenesis. Interestingly, the agar's hardness influences the morphology exhibited by these formations, with high agar concentration $(1.5 \%, 15 \mathrm{~g} / \mathrm{L})$ suppressing its development. This new auto-aggregative $E$. coli's behaviour does not require the ac-

\footnotetext{
"Corresponding author.
}

How to cite this paper: Gómez, J.M.G. and Amils, R. (2014) A Novel Cellular Autoaggregative Developmentally CRP Regulated Behaviour Generates Massively Chondrule-Like Formations over Surface of Old Escherichia coli K-12 Macrocolony Biofilms. Advances in Bioscience and Biotechnology, 5, 727-739. http://dx.doi.org/10.4236/abb.2014.59086 
tivity of the biofilm master regulator CsgD, the adhesiveness of flagella, pili type 1, adhesin Ag43, $\beta$-1,6-N-acetyl-D-glucosamine polymer-PGA, cellulose or colanic acid, but it is under glucose repression and the control of cAMP receptor protein (CRP). The possible physiological role of these chondrule-like formations in the adaptability of the colony to different stressful environmental conditions is discussed.

\title{
Keywords
}

\author{
Biofilms, E. coli Volcano-like morphotype, Macrocolony, Autoaggregation, Chondrule-Like \\ Formations, CRP Regulated Behaviour, Ag43 Independent Autoaggregation, \\ $\beta$-1,6-N-Acetyl-D-Glucosamine Polymer (PGA) Independent Autoaggregation
}

\section{Introduction}

Biofilms are multicellular communities of matrix-enclosed microorganisms that interact closely and are attached as a whole, to a biological or inorganic surface [1]. In Escherichia coli, the biofilm matrix is composed of extracellular polymeric substances (EPS), including adhesions (type 1 pili, antigen Ag43), amyloid-forming proteins (curli fibres) and exopolysaccharides ( $\beta$-1,6-N-acetyl-D-glucosamine polymer-PGA-, cellulose, colanic acid) that serve as connecting agents [2]. The bacterial adhesion to surfaces is mediated by the matrix, interconnecting and transiently immobilizing biofilm cells, providing mechanical stability to biofilms [3]. Importantly, biofilms are a sessile lifestyle that provides microorganisms with multiple protective advantages under different kinds of external stresses [1]. For instance, during treatment with antibiotics, the antibiotic resistance exhibited by biofilms impedes the eradication of persistent infections [4].

The term morphotype refers to specific properties of colonial development that generate a characteristic visual appearance [5]. E. coli bacteria grown for several days on agar surfaces develop macrocolonies, a kind of biofilm showing a strikingly elaborate three dimensional pattern, with intricate morphological architectures [6]-[9]. It has been suggested that this colonial structures should allow microorganisms to expand efficiently by taking advantage of any nutritional available resource. [5]. It has been considered that these "laboratory strain biofilms" resemble biofilms growing in natural settings on organic material that provides both support and nutrients [6]. It is well established that the $E$.coli macrocolony 3-D morphology depends on a self-produced extracellular matrix of EPS components [7] [10]. This kind of bacterial formation is a good experimental model with which to study the results of the information exchange between the micro-level (individual cells) and the macro-level (the colony) [5]. However, the way this exchange is produced remains poorly understood.

A detailed study of the development of old E. coli K-12 W3110 strain macrolony biofilms (which do not produce cellulose), and their derivate AR3110 strain (a producer of cellulose) on the surface of salt-free LB agar $(1.5 \%, 15 \mathrm{~g} / \mathrm{L})$ Petri plates has been published recently [7] [8]. These studies have revealed that amyloid curli fibers and exopolysaccharide cellulose either alone or in combination determine which three-dimensional structural elements arise in the derived macrocolony biofilm of these E. coli K-12 strains [7] [8].

Despite the fact that many insights into the biology of the $E$. coli bacteria have been obtained by growing this bacteria on hard agar surfaces (typically a 1.5\%, 15 g/L-agar concentration) [7] [8], the properties exhibited by $E$. coli colonies depend strongly on nutritional and environmental conditions e.g., viscosity or hardness of agar, availability of glucose [9] or peptone [11], in such way that its "colonial morphospace" remains still poorly explored.

Recently, we have reported a novel morphotype exhibited by old macrocolony biofilms of $E$. coli K-12 strains named volcano-like [9]. In this study, we have microscopically investigated these colonies and discovered that an autoaggregative process that generates massive chondrule-like formations on their surfaces appears to follow a spatiotemporal controlled program of development during the macrocolony morphogenesis. By using defective mutants in the production of the major EPS components of the E. coli K-12 biofilm matrix, we have determined that this cellular autoaggregative phenomenon takes place in the absence of canonical EPS components. Furthermore, the effect of agar concentration, the availability of D-(+)-glucose and the regulatory role of cAMP receptor protein (CRP) in chondrule-like formation and volcano-like morphology development have been studied. 


\section{Materials and Methods}

\subsection{Bacterial Strains, Media and Growth}

The Escherichia coli K-12 strains used in this study are detailed in Table 1. The behaviour of each mutant strain in the volcano-like and chondrule-like formation process was compared with its respective wild-type strain. Experiments were conducted using the following protocol: cells obtained from a colony of diverse E. coli K12 strains (Table 1) grown in Luria-Bertani medium [12]: $10 \mathrm{~g} / \mathrm{L}$ (1.0\%) Difco ${ }^{\circledR}$ Bacto-Trypone, 0.5\% (5 g/L) Difco $^{\circledR}$, Yeast Extract and $\mathrm{NaCl}$ 0.5\% (5 g/L) harnessed with 1.5\% (15 g/L) of Agar Bacteriológico Europeo (ABE) were inoculated with a toothpick at the centre of an 8.5-cm Petri dish made of polystyrene plastic (Sterilin ${ }^{\circledR}$ Company, http://www.sterilin.co.uk) containing $30 \mathrm{ml}$ of LB medium jellified with the indicated ABE concentrations. Plates were sealed with parafilm ${ }^{\circledR}$ to prevent loss of water. After 7 or 14 days of incubation at $37^{\circ} \mathrm{C}$, the plates were photographed with reflected light with a digital Kodak EasyShare Z710 camera. D-(+)-glucose 0.5\% (5 g/L) (provided by Merck Company) was added to LB medium when indicated.

\section{Table 1. Escherichia coli K12 strains used in this study.}

\begin{tabular}{|c|c|c|}
\hline E. coli Strains & Relevant genotype & Source or reference \\
\hline MG1655 & $\lambda^{-} r p h-1$ Wild-type ${ }^{*}$ & $\begin{array}{l}\text { J. M. Ghigo [13] } \\
\text { H. Suzuki [14] } \\
\text { G. Storz [15] } \\
\text { S. Gottesman [16] }\end{array}$ \\
\hline MG1655csgD & $\Delta \operatorname{csg} D::$ aadA Spec $^{\mathrm{r}}$ & J. M. Ghigo \\
\hline GSO548 & MG1655 $\Delta r p o S:: k a n$ & G. Storz \\
\hline GSO549 & MG1655 $\Delta c r p:: c a t$ & íd. \\
\hline GSO551 & MG1655 $\Delta p g a A:: k a n$ & íd. \\
\hline GSO569 & MG1655 $\triangle a b g R-y d a L:: k a n$ & íd. \\
\hline NM525 & Wild-type ${ }^{*}$ & íd. \\
\hline GSO553 & NM525 $\Delta$ flhDC:.kan & íd. \\
\hline GSO554 & NM525 $\Delta c s g D:: k a n$ & íd. \\
\hline SK598 & $\Delta$ fliC::FRT-kan+-FRT & H. Suzuki \\
\hline SK650 & $\Delta$ fimA::FRT-kan+FRT & íd. \\
\hline W3110 & Wild-type $^{*}$ & R. Hengge [7] \\
\hline AR120 & W3110 $\Delta$ fliC::kan & íd. \\
\hline UGB52 & MG1655 agn $43^{+*}$ & C. Beloin [17] \\
\hline UGB2836 & MG1655 dagn43::cat, $\mathrm{Cm}^{\mathrm{R}}$ & íd. \\
\hline NRD356 & MG1655 $\Delta c r p:: c a t$ & S. Gottesman \\
\hline NRD345 & MG1655 $\Delta c y a R:: c a t$ & íd. \\
\hline DJ480 & MG1655 $\Delta l a c X 74^{*}$ & íd. \\
\hline CV600 & 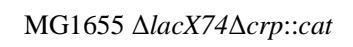 & íd. \\
\hline JMØЗ & BW25113 $\lambda^{\mathrm{i} 434}$ single lysogen & S. L. Svenningsen [18] \\
\hline JMØ11 & JMØ3 rcsA::cat & íd. \\
\hline
\end{tabular}

*Wild-type to chondrule-like formation and volcano-like macrocolony biofilms development. íd., ídem abbreviation. 


\subsection{Microscopy Techniques}

The microscopic images were taken with an Ultralyt ULNM-90-10000 microscope (Brown \& Crown Company). The images of the figures were framed with Microsoft Photo Editor Software and composed using the Powerpoint software program.

\section{Results and Discussion}

Figure 1(A) and Figure 1(B) show two different top views of a 14-day-old macrocolony of E. coli K-12 MG1655 strain developed on semisolid agar surface under the growth conditions previously defined (see Methods, [9]). A characteristic "volcano-like" morphotype [9] can be seen. Typically this macrocolony biofilm pattern shows a circular "caldera" and different "ejections" in the form of wedges (sectors) [6]. Notably, the "ejections" emerge from the "caldera" ring" to different levels of the colony slope (Figure 1(A) and Figure 1(B)), with "deep valley-gorges" separating the different ejections (Figure 1(B)). Intriguingly, the calderal ring does not surround the inoculation point; rather it is situated peripherally to the caldera centre. Indeed, this point is part of the exterior ring of the caldera.

To gain information about how the cells are spatially organized in this morphological pattern, a microscopic optical study of the surface of this biofilm macrocolony was carried out in situ under the optical microscope at different magnifications (Figures 1(C)-(F)). The first conspicuous structure observed on the surface was the massive apparition of lumpy structures (Figure $1(C)$ ). Because these lumpy formations resemble round grains of sand (chondrules) we refer to them as a chondrular-like morphology. The detailed study of microscopic images at different magnifications suggests that the apparition of chondrule-like formations could follow a development program during the macrocolony morphogenesis. To learn more about this point, we carried out a study of a volcano-like colony in an early step of macrocolony biofilm development. As shown in Figure 2, the apparition of these chondrules-like structures over the surface during the growth of a 7-day-old macrocolony appears to follow a well defined pattern of development. Thus, inside the "caldera" in the geographical center of the colony, in the innermost interior, these formations are barely visible, with the colony surface appearing as a smooth naked area (Figure 2(B)). This region is followed by a zone placed at a certain distance from the caldera center
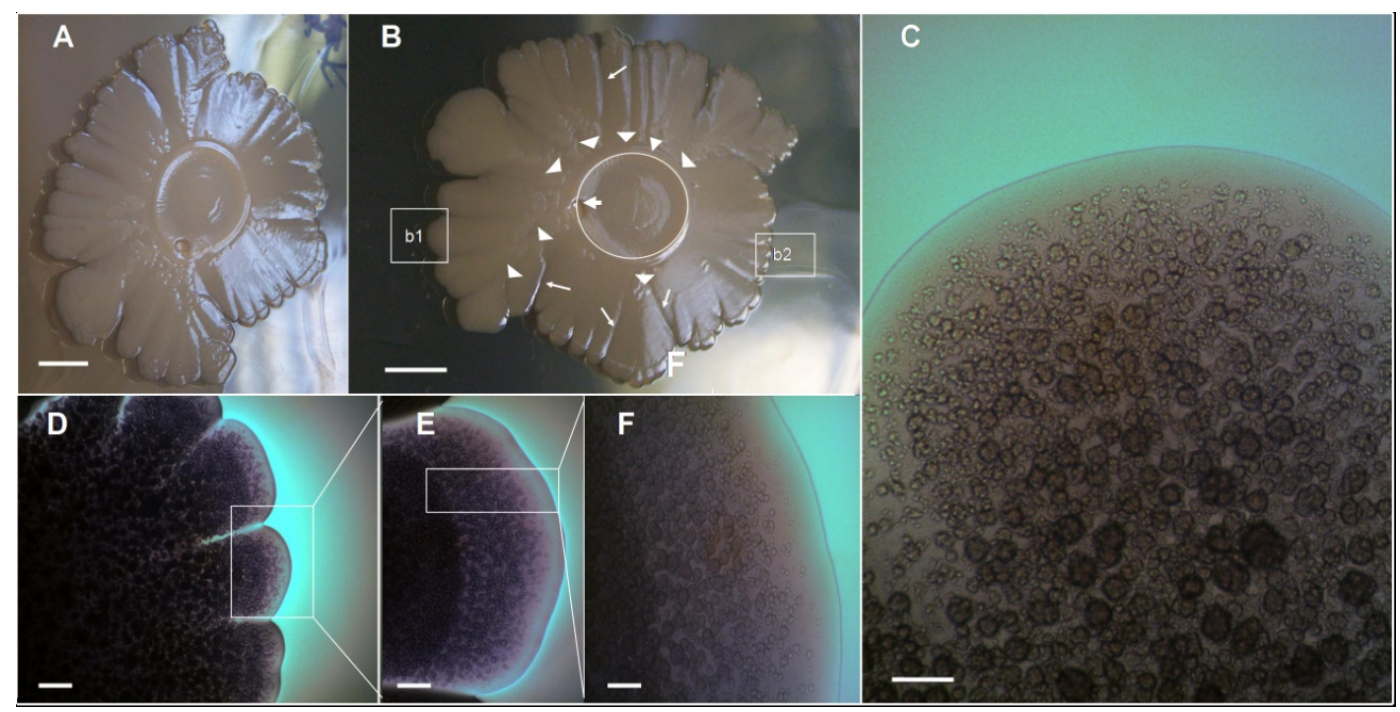

Figure 1. The volcano-like Escherichia coli K-12 macrocolony biofilms exhibit massive chondrule-like formations on its surface. (A)-(B) Two different top-views of an Escherichia coli K-12 MG1655 strain, 14-day-old volcano-like macrolony biofilm with "ejections", grown on ABE $0.6 \%$ semisolid agar surface at $37^{\circ} \mathrm{C}$ [9]. In (B) the inner circle marks the location of the "calderal ring" and the arrowheads show the points where ejections emerge, while the arrows indicate the initial inoculation point of the colony. The tiny arrows indicate the position of the different "valley-gorges"; (C) Enlargement of box b1 in (B) with a characteristic surface field showing massive chondrule-like formations on surface. (D)-(F) Zooming vista of the box b2 in (B); the images show the macrocolony surface with massive chondrule-like formations at different magnifications. Scale bars, (A) (B) $0.5 \mathrm{~cm}$; (C) (F) $\times 100,200 \mu \mathrm{m}$; (D) $\times 20,800 \mu \mathrm{m}$; (E) $\times 40,400 \mu \mathrm{m}$. 


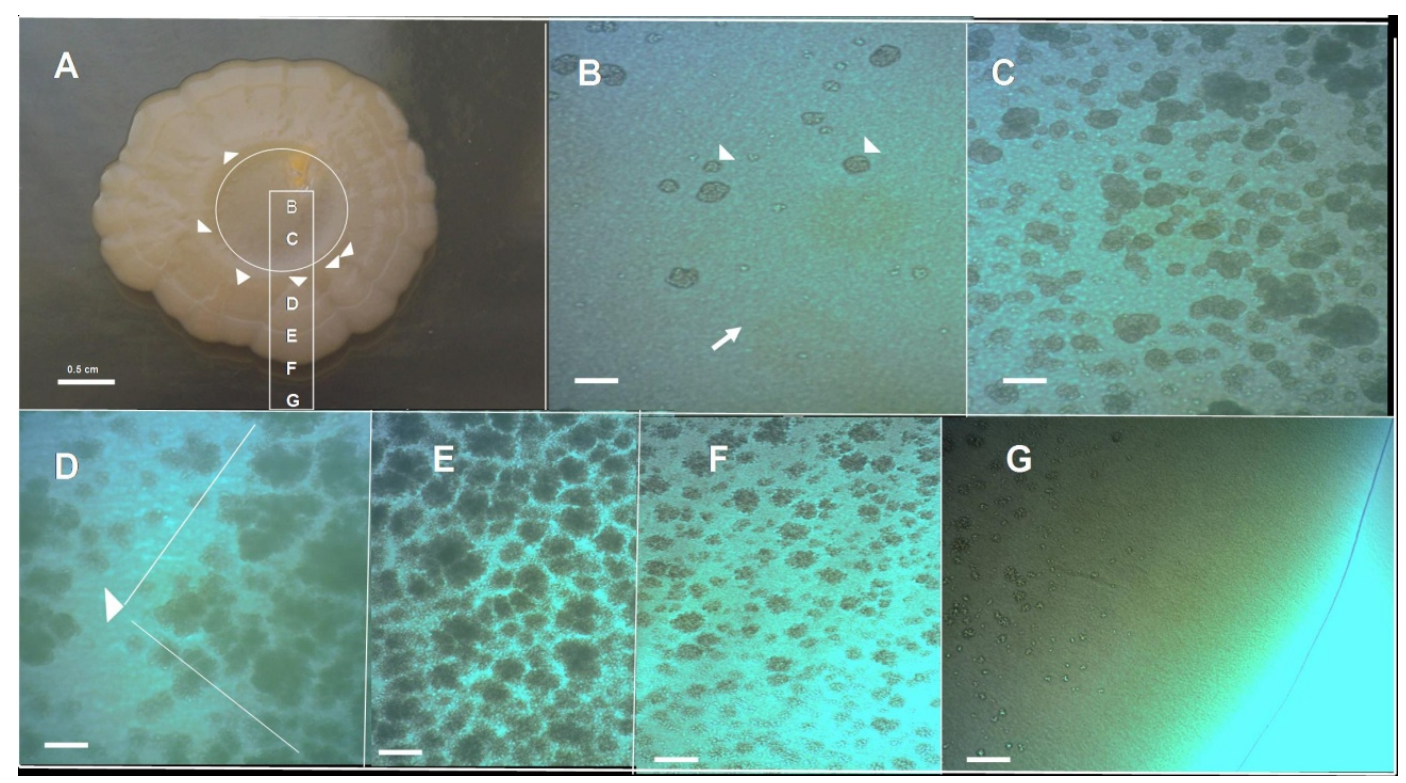

Figure 2. Chondrule-like formations in a 7-day-old volcano-like macrolony biofilm. (A) A 7-day-old volcano-like E. coli MG1655 K-12 strain macrolony biofilm grown on $0.6 \%$ ABE semisolid agar surface. (B)-(G) Microscopic close up of the zones marked in (A) showing the different level of maturation of chondrule-like formations along the colony, from the center to the edge; The arrow in (B) indicates the colony surface and the arrowheads indicate two chondrule-like formations in the process of generation. Magnifications and scale bars, (A) $0.5 \mathrm{~cm}$; (B)-(G) $\times 100,200 \mu \mathrm{m}$.

in which lumpy formations suddenly begin to emerge massively, increasing in size toward the edge of the colony and thus forming the ring of caldera (Figure 2(C)). Beyond the coronal ring it is possible to observe the roots (typically triangular) from which the wedged ejections are produced (Figure 2(D)). Along an ejection the appearance of clumpy formation again follows a clear fixed pattern: increase in density toward the edge of the colony, but decreasing in number near the edge of the colony where these formations are not present (Figures 2(E)-(G)). In fact, the outer edge of a mature macrocolony show a "shoreline" with the appearance of an area devoid of chondrule like structures (Figure 2(G)).

After seven additional days of development the colony become flatter, although maintaining their volcanolike morphotype, show an increase in the roughness of the colonial perimeter with consolidation of ejections (compared Figure 2(A) versus Figure 1(A) and Figure 1(B)). Notably, the gorges that separate the different ejections appear to be well consolidated (Figures 3(A)-(C)) and interestingly, there is no formation of chondrule-like structures on the floors inside valley-gorges (Figures 3(D)-(K)). More importantly, the chondrulelike structures appear to be more tightly packed toward the end of a valley-gorge (Figure 3(K)), indicating the existence of a maturation process during the generation of these structures, which appear to be related to the age of the macrocolony.

Taken together these results suggest that the autoaggregative process that generates these chondrule-like formations begins at the edge of the colony and acts during the development of the macrocolony to increase the size and tightness of these chondrular structures, indicating that the morphogenesis of volcano-like macrocolony aerial E. coli biofilms is a complex developmental process that entails a massive lumpiness developed under a tightly controlled space-temporal orchestration.

To gain additional insight into the microscopic structure of the chondrule-like formations, a piece of a colony was carefully removed and the chondrule-like formations were observed at higher magnification under a microscope coverslip. As shown in Figure 4, these formations are constructed by the autoaggregation of bacterial cells (which can be distinguished at the cellular level after its mechanical disintegration, by the pressure of coverslip, Figure 4(D) and Figure 4(G)) which interact strongly and tightly to form the chondrule-like structures (Figure 4(B) and Figure 4(E)). Cells remain apparently attached by some yet undescribed adhesive substance(s) (Figure 4(C) and Figure 4(F)).

Next, to be investigated was whether the agar concentration (hardness) could influence the appearance of 


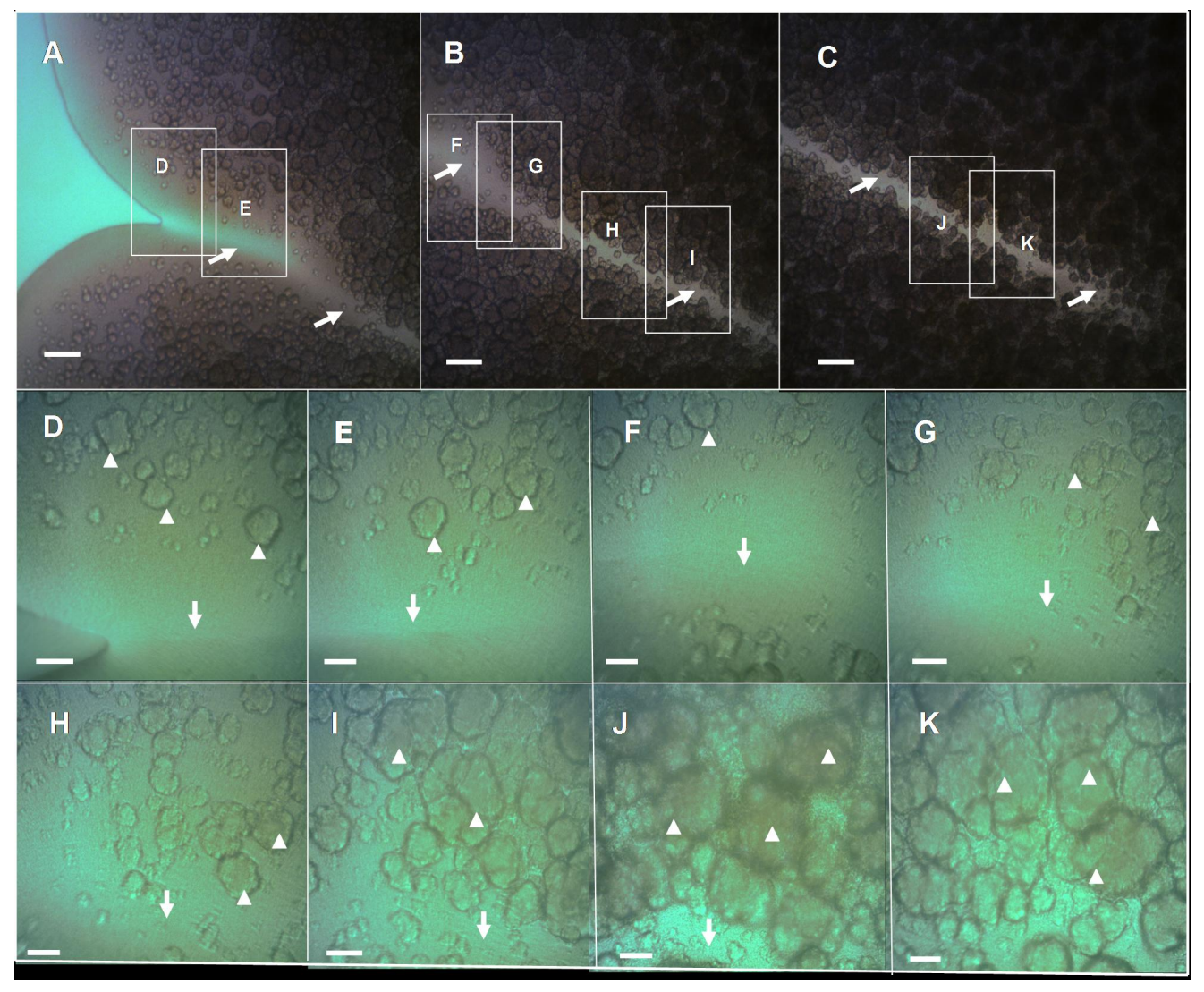

Figure 3. Close-up view of a "valley-gorge" with chondrule-like formations exhibiting different levels of maturity, in a volcano-like 14-old-day macrocolony biofilm. (A)-(C) A complete valley-gorge of a volcano-like E. coli K-12 MG1655 strain macrocolony biofilm 14-day-old is shown in these images obtained directly in situ under the optical microscope. (A) The entrance to the valley-gorge on the edge of the macrocolony (B) Middle zone (C) The end, situated inside colony toward its center. The arrows indicate the "floor" of the valley-gorge where the chondrule-like formations are not observed. (D)-(K) Enlargement of the boxes indicated in (A)-(C), the arrowheads indicate the chondrule-like formations that show different levels of maturity along of the valley-gorge. Magnifications and scale bars, (A)-(C) $\times 100,200$ $\mu \mathrm{m}$; (D)-(K) $\times 400,40 \mu \mathrm{m}$.

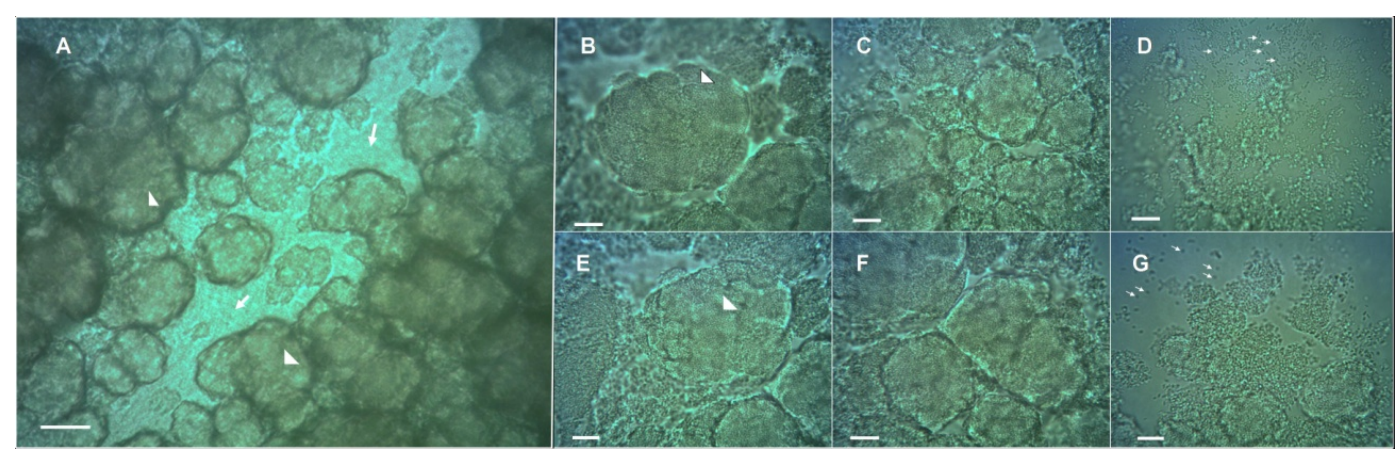

Figure 4. Chondrule-like formations are made of tightly packed auto-aggregated bacterial cells. (A) Typical chondrule-like formations observed in situ in a "valley-gorge" over surface of a volcano-like E. coli MG1655 strain 14-old-day macrocolony biofilm. The arrows indicate the "floor of the valley-gorge", whereas arrowheads mark typical mature chondrule-like formations. (B)-(G) The chondrule-like formations were extracted from the colony, deposited on the surface of a glass microscope slide and observed at $\times 1000$ magnification. In (B) (E) the arrowheads indicate a chondrule-like formation; In (C)-(F) the images show the chondrule-like formation in different level of disaggregation. The tiny arrows in (D)-(G) indicate single cells. Magnifications and scale bars, (A) $\times 400,40 \mu \mathrm{m}$; (B-G) $\times 1000,20 \mu \mathrm{m}$. 
these autoaggregative formations. To test this, E. coli K-12 MG1655 strain was grown in Petri dishes prepared with different agar concentrations in LB medium. The increase of the ABE agar concentration from $0.6 \%$ (6 $\mathrm{g} / \mathrm{L})$ to $1.0 \%(1.0 \mathrm{~g} / \mathrm{L})$ (Figure 5(A)) has an impact on the appearance of the chondrule-like formations, which acquire an ovoid geometry similar to a rugby ball (Figures 5(C)-(E)). Remarkably, when the ABE agar concentration was increased to 1.5\% (15 g/L) (Figure 5(F)) the chondrule-like formations were completely abolished (Figures $5(\mathrm{G})-(\mathrm{J})$ ). Altogether these results indicate that the formation of chondrule-like structures is influenced by the agar hardness (i.e., the viscosity of the medium), apparently increasing the package when the agar concentration increases, and suppressing its formation at high agar concentration.

Interestingly, when cells extracted from these volcano-like macrocolonies were smeared on a glass microscope slide, they were able to form "bubbles", within an extremely thin film of $E$. coli cells that encloses air in a hollow sphere (Figures 6(A)-(J)), indicating that these "E. coli bubbling cells" exhibit a strong adhesiveness which has not been previously reported and that will be object of study in future experiments. This high cellular

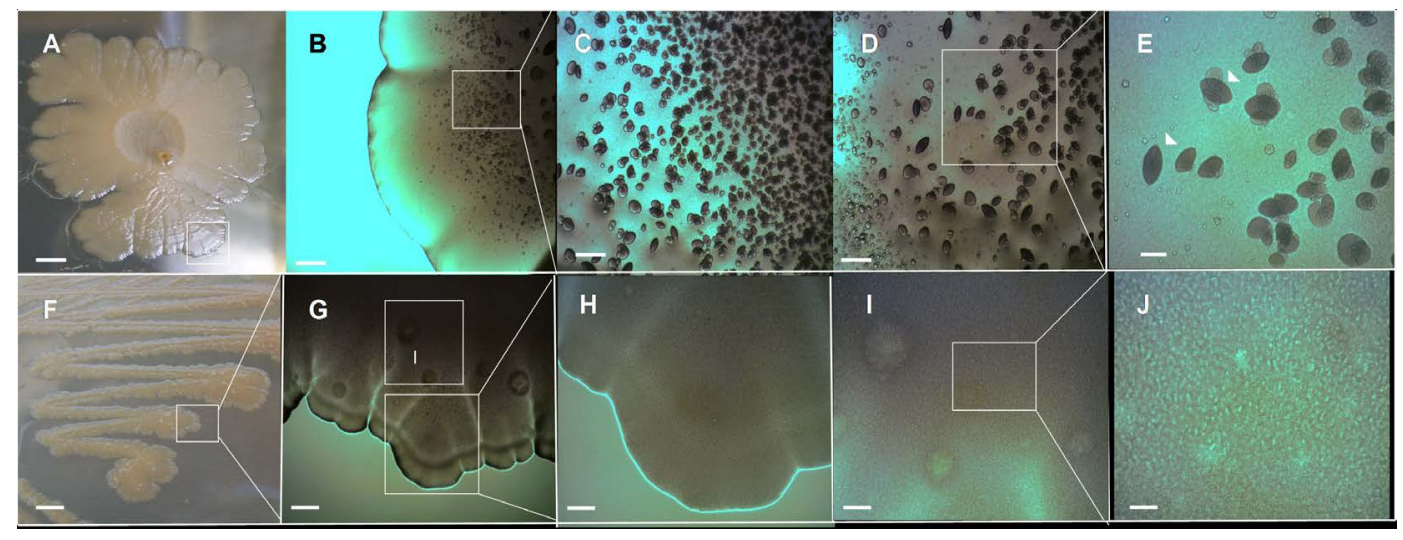

Figure 5. Effect of agar hardness on E. coli chondrule-like formation and on the appearance of its morphological pattern. (A) Typical volcano-like E. coli K-12 MG1655 strain 14-day-old macrocolony biofilm grown on a $1.0 \% \mathrm{ABE}$ agar surface at $37^{\circ} \mathrm{C}$. (B)-(E) Close up of chondrule-like formation on surface of this colony. (E) The typical chondrule-like formations showing a characteristic ovoid "rugby ball” morphology is indicated by arrowheads. (F) A typical E. coli K-12 MG1655 strain 14-day-old macrocolony biofilm grown on a $1.5 \%$ ABE agar surface at $37^{\circ} \mathrm{C}$. (G)-(J) Close up of surface of this colony devoid of chondrule-like formations. In $(\mathrm{G})$ the box marked as (I) is enlarged in the image (I). Magnifications and scale bars, (A) (F) $0.5 \mathrm{~cm}$; (B) $(\mathrm{G})$ $\times 40,400 \mu \mathrm{m}$; (C) (D) (H) (I) $\times 100,200 \mu \mathrm{m}$; (E) (J) $\times 400,40 \mu \mathrm{m}$.

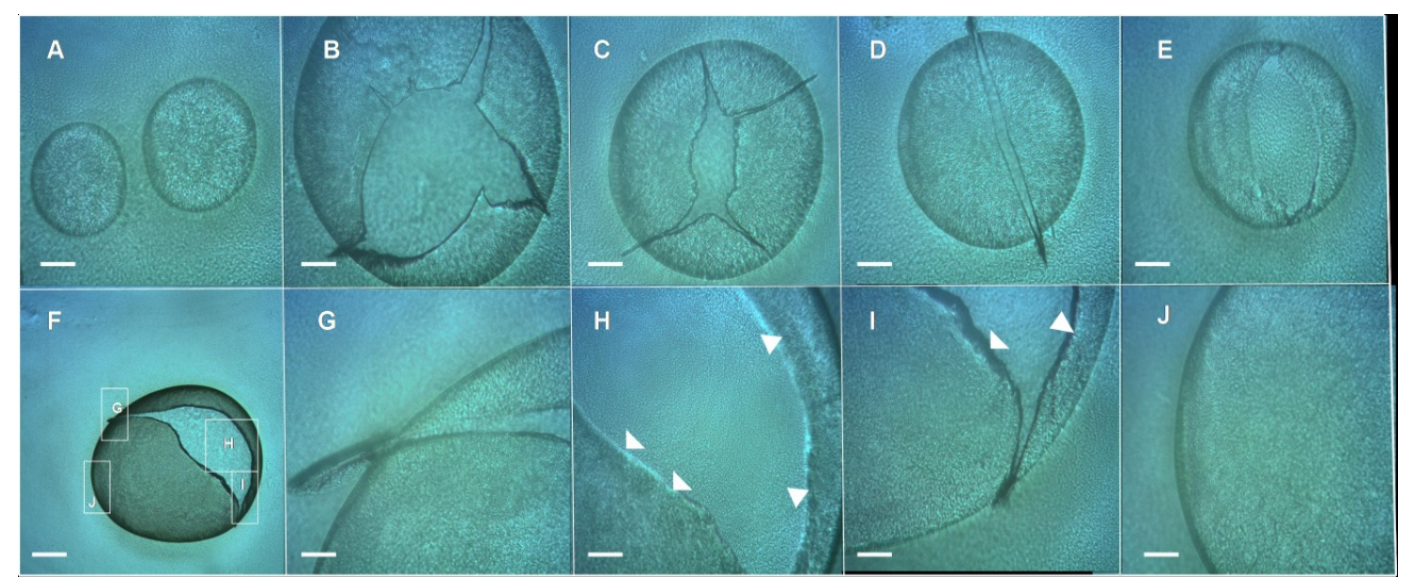

Figure 6. E. coli “bubbles”. (A)-(I) Cells extracted from E. coli K-12 MG1655 strain volcano-like macrocolony biofilm 14-day-old smeared on glass microscope slide show a strong adhesiveness forming $E$. coli "bubbles". (A) Two intact E. coli bubbles; (B)-(E) Different punctured E. coli bubbles; (F) A punctured E. coli bubble in a lower magnification; $(\mathrm{G})-(\mathrm{H})$ Enlargements of the box indicated in (F); In (H)-(I) the arrowheads indicate the wall of the bubbles formed by E. coli cells. Magnifications and scale bars, (A)-(E) and (G)-(J) $\times 100,200 \mu \mathrm{m}$; (F) $\times 40,400 \mu \mathrm{m}$. 
adhesiveness can explain the in situ appearance of the surface of the macrocolony (e.g., Figure 2(B) or the Figures 3(D)-(G), Figure 4(A)) where the chondrule-like formations were not observed and instead, exhibited a smooth surface probably due to the strong interaction between cells. Hence, this ability for a strong adhesive contact between cells of a volcano-like macrocolony could also explain the initial tendency of these cells to form autoaggregates.

It has been recently documented that a high-level of curli production is a prerequisite for the formation of wrinkles and ring-like structures in macrocolony biofilm of the W3110 strain grown in a salt-free LB medium below $30^{\circ} \mathrm{C}$ [7] [8]. Also the flagella and pili contribute to the shaping of the three-dimensional architecture of this macrocolonies [7]. In E. coli K-12, the curli production is regulated by the biofilm master regulator CsgD

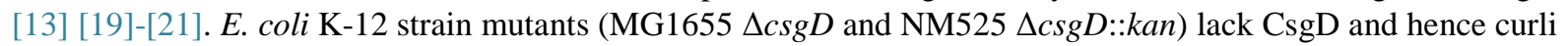
production, develop a volcano-like morphotype similar to the one shown in Figure 1(A) and Figure 1(B), and produce normal levels of chondrule-like structures (data not shown), indicating strongly that curli are not required to generate these volcano-like macrocolony biofilm and chondule-like structures. This conclusion is reinforced because a mutant MG1655 $\Delta r p o S:: k a n$ strain that lacks of the RpoS $\left(\sigma^{\mathrm{S}}\right)$ factor which controls the $\operatorname{csg} D$ expression [20], showed a phenotype indistinguishable from the wild-type strain, indicating additionally that RpoS is not necessary for the development of volcano-like morphology and chondrule-like formations.

We next determined whether other components of the canonical E. coli K-12 biofilm matrix could be involved in chondule-like formations and the development of volcano-like morphology. To test this hypothesis, the E. coli K-12 strain mutants (see Table 1) that lack the capacity to produce the following EPS components and bacterial surface appendages: type 1 pili (MG1655 $\triangle$ fimA, FimA is the major subunit of this kind of fimbriae) [14], flagella (W3110 $\Delta$ fliC mutant strain that is unable to produce flagellin-FliC-and therefore does not assemble flagellar filaments [7] and MG1655 $\Delta$ flhDC mutant that does not express any flagellar genes [15]), $\beta$-1,6-N-acetyl-D-glucosamine polymer-PGA- (MG1655 $\Delta p g a A:$ :kan, PgaA is the porin through which PGA exopolysaccharide is excreted [22]) and colanic acid (JMØ3 rcsA::cat, lacking of RcsA, an activator of genes for colonic acid synthesis [18] [23]) were grown in LB ABE $0.6 \%$ for 14 days at $37^{\circ} \mathrm{C}$ and compared with their respective wild-type strains. All mutant strains developed the same volcano-like morphologies and normal levels of chondrule-like formations on their macrocolony surfaces as their correspondent wild-type strains. The obtained results (data not shown) indicates that these matrix elements are not required for the formation of volcano-like morphology and the development of chondrule-like formations on the surface of this type of macrocolony biofilms.

Another component involved in biofilm formation in E. coli is the antigen 43 (Ag43) [2]. This is an abundant outer membrane auto-transporter adhesin present in most commensal and pathogenic E. coli strains [24]. Antigen-43 has been implicated in the auto-aggregation of cells and cell-to-cell interactions [25] thus influencing the morphology of E. coli colonies [26]. To test the hypothesis that Ag43 could be mediating the chondrule-like formation, the ability of the E. coli strain UGB2836 (MG1655 $\Delta a g n 43$ ) lacking the agn43 (flu) gene encoding Ag43 [17] was compared with its wild-type strain for the development of volcano-like colonies and chondrule-like formations. The strain lacking Ag43 showed behaviour similar to that of the wild-type strain (data not shown), indicating that this auto-transporter adhesin is not involved in the generation of these colonial structures.

Taken together, these results indicate that the formation of a chondrule-like and volcano-like morphotype is independent of the activity of major EPS components that form the canonical biofilm matrix of the E. coli K-12 strains.

It is well known that carbon metabolisms play an important role in biofilm formation [27]. Catabolite repression (CR) is the preferential utilization of glucose as a carbon source by bacteria [28]. When glucose is available in the nutritive medium, uptake and utilization of alternative carbon sources are repressed [12] [27]. In E. coli, the synthesis of cyclic AMP (cAMP) by adenylate cyclase (Cya) is inhibited by the presence of the preferred catabolite glucose, and the levels of cAMP and therefore the DNA binding activity of the cAMP receptor protein (CRP) are high when poor carbon sources are available and low when glucose is present in the medium. It has been reported previously that catabolite repression plays an important role in the regulation of multilayer biofilm formation of several species of Enterobacteriaceae and laboratory strains of E. coli [29]. And that the catabolite repression in E. coli biofilm formation is mediated in part by cAMP and CRP [29].

In a previous report, we have described that the D-(+)-glucose when supplied to LB medium has a strong impact on the colony's morphotypical appearance [9]. The volcano-like morphotype is disrupted and its formation 
is completely abolished, exhibiting a "soft" delicate colony form (Figure 7(A)) [9]. Optical microscopy observation of the surface of these "soft" colonies demonstrated that the emergence of chondrule-like formation was completely abolished (Figures 7(B)-(E)). To determine whether the glucose inhibiting effect on the chondrulelike formation and macrocolony volcano-like formation was subject to classical catabolite repression via cAMPCRP complex, the abilities of three different E. coli K-12 strains GSO549, NRD356 and CV600 (all carrying a chromosomal $\Delta c r p$ mutation, see Table 1) to develop these colonial formations were compared with their wild-type strain. As shown in Figure 7(F) the mutation $\Delta$ crp has a strong impact in the morphology of the macrocolony biofilm that severely disrupts the volcano-line morphology (Figure 7(F)). Notably, no ejections or chondrular-like formations were observed except for some residual formations on the surface of the MG1655 $\Delta c r p$ mutant colony (see Figures 7(G)-(I) compared with the wild-type strain Figures 7(J)-(L)).

Taken together these results strongly suggest that the formation of chondrule-like and volcano-like macrocolony biofilms formation is under catabolic repression, requiring the transcriptional regulatory activity of cAMP receptor protein. This conclusion is strongly supported because three different $E$. coli K-12 strains carrying $\Delta c r p$ mutations constructed in different laboratories showed the same phenotype.

In addition, it has recently been described that CRP is able to indirectly regulate the expression of many genes via control of expression of noncoding regulatory small RNA (sRNA), such as CyaR [16] and McaS [15], thereby expanding the gene repertoire controlled by this transcriptional regulatory protein. For instance, CRP indirectly regulates the expression of different genes (e.g., ompX encoding the outer membrane OmpX, probably related with adherence cellular), quorum sensing (e.g., luxS, LuxS synthesizes AI-2 autoinducer, a small molecule used in quorum sensing in E. coli and others bacteria) and nitrogen assimilation (e.g., nadE, which product NadE enzyme uses ammonia to catalyze the last step in NAD synthesis) through activation of the expression of the sRNA CyaR [16]. The strain MG1655 $\triangle c y a R$ lacking CyaR showed a normal behaviour for the production

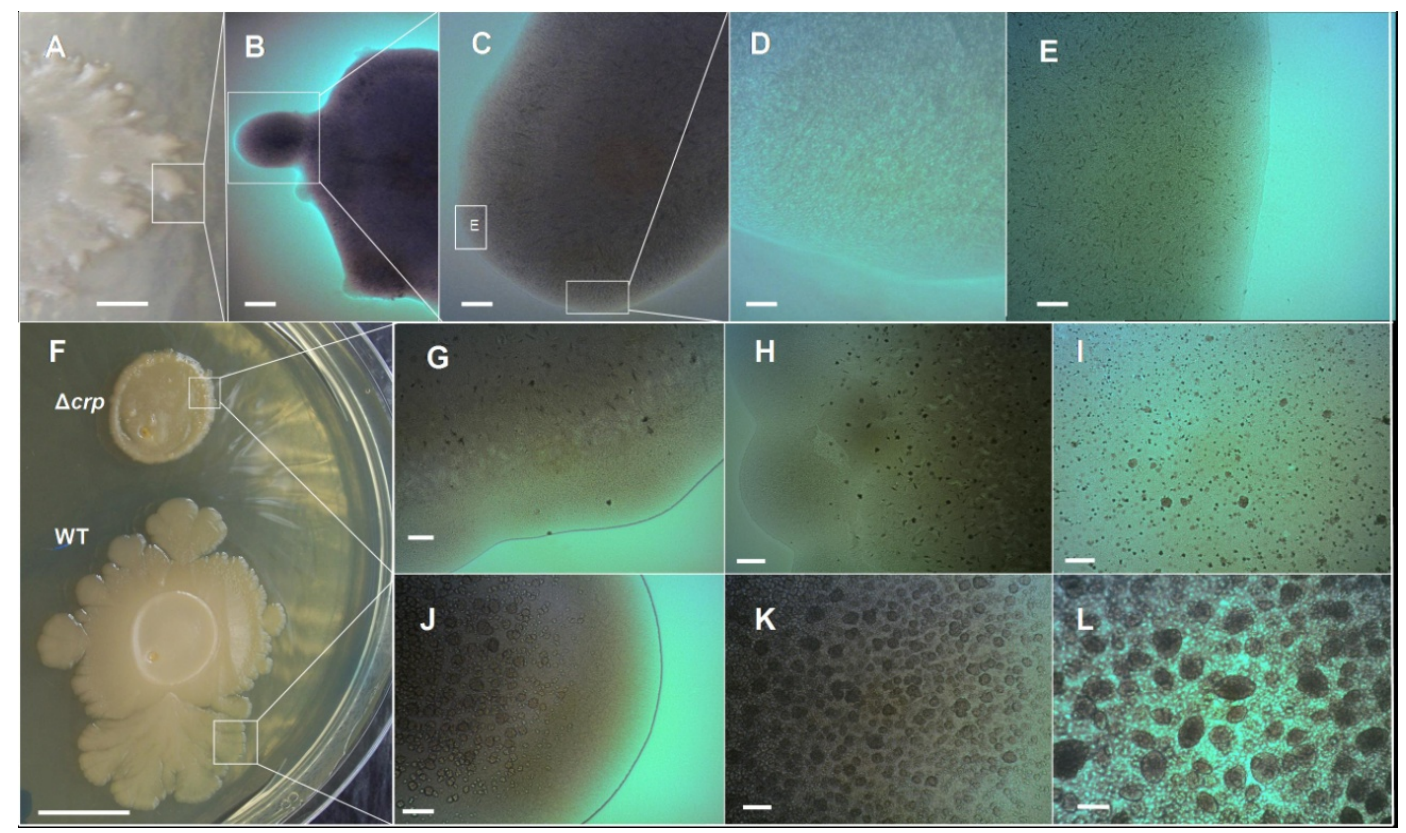

Figure 7. The generation of the E. coli K-12 volcano-like morphotype and chondrule-like formations are both under catabolic repression. (A)-(E) D-(+)-glucose suppresses chondrule-like formation. (A) Typical morphotype of a wild-type $E$. coli K-12 MG165514-day-old grown at $37^{\circ} \mathrm{C}$ on ABE $0.6 \%$ semisolid surface in LB medium supplemented with $0.5 \%$ D-(+)-Glucose; (B)-(E) Zooming vista of the surface of this macrocolony biofilm; (E) Enlargement of the box indicated in (C) as box (E). (F)-(L) cAMP receptor protein (CRP) controls the formation of volcano-like macrocolony morphotype and of the chondrule-like formations; (F) Typical macrocolony morphology of E. coli K-12 MG1655 $\Delta$ crp strain 14-day-old compared with the wild-type MG1655 crp+ strain grown both on $0.6 \%$ ABE semisolid surface at $37^{\circ} \mathrm{C}$; (G)-(I) Close up of surface of a MG1655 $\Delta$ crp strain macrocolony; (J)-(L) Close up of the surface of a volcano-like MG1655 crp+ wild-type strain macrocolony biofilm. Magnifications and scale bars; (A) $0.25 \mathrm{~cm}$; (B) $\times 20,800 \mu \mathrm{m}$; (C) $\times 40,400 \mu \mathrm{m}$; (D) (E) (I) (L) $\times 400,40 \mu \mathrm{m}$; (F) $1.0 \mathrm{~cm}(\mathrm{G})(\mathrm{H})(\mathrm{J})(\mathrm{K}) \times 100,200 \mu \mathrm{m}$. 
of chondrule-like structures and macrocolony morphology in ABE 0.6\% (data not shown), a result that strongly indicate that the genes that are under the indirect control of CRP via activation of cyaR expression are not required for chondrule-like formation and the development of volcano-like morphology. Additionally, it has been reported that CRP regulate the expression of a sRNA called McaS that controls motility and an autoaggregative behaviour via the control of the expression of the pgaA gene [15]. To test whether the chondrule-like formation could be a phenomenon of McaS-dependent auto-aggregation, the E. coli strain MG1655 $\triangle a b g R-y d a L:: k a n$, lacking chromosomal McaS, was compared with its wild type strain for chondrule-like formation. The results (data not shown) showed that this mutant exhibits a wild-type phenotype for chondrule-like formation, indicating that this sRNA is not involved in the control of the autoaggregative behaviour that originates this kind of formations. Furthermore, this result reinforces the conclusion achieved with the mutant strain MG1655 $\Delta$ pgaA::kan previously discussed, that the exopolysaccharide $\beta$-1,6-N-acetyl-D-glucosamine polymer-PGA- is not involved in chondrule-like formation.

The results presented in this work raise two important questions to be answered in future experiments. Firstly, what are the factor(s) (e.g., adhesions) that participate in the condrule-like formation? Secondly, how does this factor(s) mediate the chondrule-like formation, growth and maturation during the development and morphogenesis of a volcano-like macrocolony biofilm?

An important clue obtained from this work is that chondrule-like formation is under catabolic repression (Figure 7). The CRP protein is a classical global transcriptional regulator affecting the expression of many genes [30]. It has been recently estimated that the total number of operons under the direct control of cAMPCRP complex range from minimum 378 to more than 500 [30]. Most of the genes that have been shown to be directly regulated by CRP are involved in the transport or catabolism of sugars or amino acids [16]. Moreover, the function of many of them remains unknown and it is likely the physiological role of these CRP-dependent orphan genes could be related with the chondrule-like formation phenomenon described here.

Interestingly, it has been demonstrated that multiple chaperone-usher cryptic but functional fimbrae are encoded in the genome of Escherichia coli K-12 [31]. The operons that encode these cryptic fimbriae $y c b, y b g, y f c$, yad, yra, sfm and yeh are silent because their expression is under repression by the global regulator H-NS (Histone-like Nucleoid Structuring protein, [32]) and, except for yad expression, additionally subjected to carbon catabolite repression mediated by activation of cAMP receptor protein (CRP) [30]. The possibility that the expression of this cryptic fimbriae or others [33] could be depressed during the development of volcano-like macrocolony biofilms and that under these conditions those fimbriae could be mediating the chondrule-like generation will be the subject of future work. Other interesting phenomenon uncovered by this work is that the viscosity of the agar affects chondrule-like formation, suggesting that there is a viscosity-dependent signalling mechanism(s) that informs to a putative chondrule-like generative mechanism(s) that trigger(s) and controls the generation of this kind of formations. The manner by which a variation in viscosity is translated into a change of bacterial behaviour is still poorly understood. Therefore, the formation of chondule-like formations represents an excellent experimental model to study and further understand the signalling molecular mechanism(s) underlying the viscosity control of autoaggregative behaviours in E. coli.

A fundamental question raised by this work is why these autoaggregative chondrule-like formations are produced by E. coli old-macrocolony biofilms? Today it is widely recognized that biofilms contain different zones that are morphologically and physiologically distinct [34]. In fact, this heterogeneity is a hallmark of the biofilm's lifestyle [35]. This phenotypical heterogeneity has been interpreted as the implementation of a bethedging strategy to achieve survival under changing environmental conditions [36] [37]. Indeed, it is considered that this heterogeneity is a manifestation of bacterial multicellulary [38] [39]. We suggest that because not all cells in the macrocolony participate in the formation of chondrule-like formations on the macrocolony, this autoaggregative behaviour represents a new phenotypical manifestation of this heterogeneity (Figure 1(C)). Typically, bet-hedging strategy happens when there is a kind of stochastic switching between phenotypic states [36]. The microscopic observations presented in this work indicate that there could be a kind of stochastic switching during the generation of the chondrule-like formations over the surface of the macrocolony biofilms (Figure 1(C)). For instance, the expression of the gene agn43 encoding the adhesion Ag43 involved in auto-aggregation in E. coli undergoes a regulated reversible switch or phase variation of the agn43 ON and agn43 OFF states [17] [24]. Whether this phenomenon also occurs during chondrule-like formation is a challenge for future research. It has been proposed that auto-aggregation may confer increased survival of the cells that form the bacterial auto-aggregating clump under different stressful conditions [40] [41] (e.g., during desic- 
cation or phage attack [42]), increasing fitness under environmental conditions that induce its formation.

Thus, it is tempting to speculate that the generation of these autoaggregative chondrular-like formations could represent a bacterial response to desiccation that $E$. coli bacteria undergo in many natural ecological niches outside of their hosts [43]. The possible functional role of this putative response would be an increase in tolerance and protection against long-term dehydration. This possibility will be explored in future investigations.

Finally, it is interesting to highlight the difference observed between the auto-aggregative behaviour described in this work with the self-aggregative behaviour called crowning that generates a self-organized corona described in our previous work [9]. Thus, while chrondrule-like and volcano-like macrocolony biofilm formation is suppressed by $\mathrm{D}-(+)$-glucose and is under the control of CRP, the corona formation is suppressed by $\mathrm{D}-(+)$-glucose but is not affected by CRP regulation [9]. Therefore, the crowning behaviour observed inside semisolid ABE agar in contact with a plastic surface [9] and the chondrular-like formation generated on the surface of an aerial macrocolony biofilm described in this work represent two different autoaggregative behaviours, that act in the same E. coli biofilm to adapt bacteria to different environmental encounters during the colonization of different ecological niches. Hence, this E. coli's duality of autoaggregative behaviours is another notable manifestation of the existence of physiological heterogeneity in bacterial biofilms [34]; likely indicating that in the same E. coli biofilms (in this case a system consisting of a macrocolony aerial biofilm and a corona interstitial agar embedded biofilm [9] there is different subpopulations of cells differentially regulated by CRP, producing thus different patterns of gene expression in these cells generating in this way a phenotypical heterogeneity to achieve adaptation and survival of biofilm as an unified interwoven multicellular bacterial community.

\section{Conclusion}

We have described the massive formation of chondrule-like formations on the surface of a volcano-like macrocolony of E. coli K-12 strain. These formations showed a developmental pattern of maturation during the morphogenesis of the volcano-like formation. They are formed by the autoaggregation of tightly packed interacting bacterial cells. It has been demonstrated that neither the adhesiveness of curli, flagella, Ag43 adhesins, PGA, cellulose nor colanic acid are required for volcano-like macrocolony biofilms development and chondrulelike formation. However, the hardness of the agar has a strong impact on the appearance of these formations, in such a way that high agar concentrations suppresse their formation. Additionally we have presented experimental evidence that D-(+)-glucose availability and the CRP transcriptional regulator are key mediators of chondrule-like formation and genesis of volcano-like morphotype. Also, a possible function for these chondrule-like formations has been suggested: to withstand and gain adaptability to desiccation and to other stressful environmental conditions, such as phage predation.

\section{Acknowledgements}

The author expresses their gratitude to J. M. Ghigo, C. Beloin, H. Suzuki, S. Gottesman, G. Storz and S. Lo Svenningsen for kindly providing the E. coli K-12 strains cited in Table 1 . There is no conflict of interest related to this research.

\section{References}

[1] López, D., Vlamakis, H. and Kolter, R. (2010) Biofilms. Cold Spring Harbor Perspectives in Biology, 2, a000398. http://dx.doi.org/10.1101/cshperspect.a000398

[2] Beloin, C., Roux, A. and Ghigo, J.-M. (2008) Escherichia coli Biofilms. Current Topic in Microbiology and Immunology, 322, 249-289. http://dx.doi.org/10.1007/978-3-540-75418-3 12

[3] Flemming, H-C. and Wingender, J. (2010) The Biofilm Matrix. Nature Reviews in Microbiology, 8, 623-633. http://dx.doi.org/10.1038/nrmicro2415

[4] Kostakioti, M., Hadjifrangiskou, M. and Hultgren, S.J. (2013) Bacterial Biofilms: Development, Dispersal, and Therapeutic Strategies in the Dawn of the Postantibiotic Era. Cold Spring Harbor Perspectives in Medicine, 3, a010306. http://dx.doi.org/10.1101/cshperspect.a010306

[5] Ben-Jacob, E., Cohen, I. and Gutnick, D.L. (1998) Cooperative Organization of Bacterial Colonies: From Genotype to Morphotype. Annual Review Microbiology, 52, 779-806. http://dx.doi.org/10.1146/annurev.micro.52.1.779

[6] Shapiro, J.A. (1997) Multicellularity: The Rule Not the Exception. Lessons from Escherichia coli Colonies. In: Shapiro, J.A. and Dworkin, M., Eds., Bacteria as Multicellular Organisms, Oxford University Press, New York, 14-49. 
[7] Serra, D.O., Richter, A.M., Klauck, G., Mika, F. and Hengge, R. (2013) Microanatomy at Cellular Resolution and Spatial Order of Physiological Differentiation in a Bacterial Biofilm. mBio, 4, e00103-13. http://dx.doi.org/10.1128/mBio.00103-13

[8] Serra, D.O., Richter, A.M. and Hengge, R. (2013) Cellulose as an Architectural Element in Spatially Structured Escherichia coli Biofilms. Journal of Bacteriology, 195, 5540-5554. http://dx.doi.org/10.1128/JB.00946-13

[9] Gómez-Gómez, J.M. and Amils, R. (2014) Crowning: A Novel Escherichia coli Colonizing Behaviour Generating a Self-Organized Corona. BMC Research Notes, 7, 108. http://dx.doi.org/10.1186/1756-0500-7-108

[10] Hung, C., Zhou, Y., Pinkner, J.S., Dodson, K.W., Crowley, J.R., Heuser, J., Chapman, M.R., Hadjifrangiskou, M., Henderson, J.P. and Hultgren, S.J. (2013) Escherichia coli Biofilms Have an Organized and Complex Extracellular Matrix Structure. mBio, 4, e00645-13. http://dx.doi.org/10.1128/mBio.00645-13

[11] Darton, N.C. (2010) Structure and Pattern in Bacterial Colonies. In: Olafsen, J., Ed., Experimental and Computational Techniques in Soft Condensed Matter Physics, Cambrige University Press, Cambrige, 279-325. http://dx.doi.org/10.1017/CBO9780511760549.011

[12] Gomez-Gomez, J.M., Baquero, F. and Blazquez, J. (1996) Cyclic AMP Receptor Protein Positively Controls gyrA Transcription and Alters DNA Topology after Nutritional Upshift in Escherichia coli. Journal of Bacteriology, 178, 3331-3314.

[13] Da Re, S. and Ghigo, J.M. (2006) A CsgD-Independent Pathway for Cellulose Production and Biofilm Formation in Escherichia coli. Journal of Bacteriology, 188, 3073-3087. http://dx.doi.org/10.1128/JB.188.8.3073-3087.2006

[14] Kurihara, S., Suzuki, H., Oshida, M. and Benno, Y. (2011) A Novel Putrescine Importer Required for Type 1 PiliDriven Surface Motility Induced by Extracellular Putrescine in Escherichia coli K-12. Journal of Biological Chemistry, 286, 10185-10192. http://dx.doi.org/10.1074/jbc.M110.176032

[15] Thomasson, M.K., Fontaine, F., De Lay, N. and Storz, G. (2012) A Small RNA That Regulates Motility and Biofilm Formation in Response to Changes in Nutrient Availability in Escherichia coli. Molecular Microbiology, 84, 17-35. http://dx.doi.org/10.1111/j.1365-2958.2012.07965.x

[16] De Lay, N. and Gottesman, S. (2009) The Crp-Activated Small Noncoding Regulatory RNA CyaR (RyeE) Links Nutritional Status to Group Behavior. Journal of Bacteriology, 191, 461-476. http://dx.doi.org/10.1128/JB.01157-08

[17] Chauhan, A., Sakamoto, C., Ghigo, J.M. and Beloin, C. (2013) Did I Pick the Right Colony? Pitfalls in the Study of Regulation of the Phase Variable Antigen 43 Adhesin. PLOS ONE, 8, e73568. http://dx.doi:10.1371/journal.pone.0073568

[18] Høyland-Kroghsbo, N.M., Mærkedahl, R.B. and Svenningsen, S.L. (2013) A Quorum-Sensing-Induced Bacteriophage Defense Mechanism. mBio, 4, e00362-12. http://dx.doi:10.1128/mBio.00362-12

[19] Brombacher, E., Baratto, A., Dorel, C. and Landini, P. (2006) Gene Expression Regulation by the Curli Activator CsgD Protein: Modulation of Cellulose Biosynthesis and Control of Negative Determinants for Microbial Adhesion. Journal of Bacteriology, 188, 2027-2037. http://dx.doi.org/10.1128/JB.188.6.2027-2037.2006

[20] Pesavento, C., Becker, G., Sommerfeldt, N., Possling, A., Tschowri, N., Mehlis, A. and Hengge, R. (2008) Inverse Regulatory Coordination of Motility and Curli-Mediated Adhesion in Escherichia coli. Genes \& Development, 22, 24342446. http://dx.doi.org/10.1101/gad.475808

[21] Ogasawara, H., Yamamoto, K. and Ishihama, A. (2011) Role of the Biofilm Master Regulator CsgD in Cross-Regulation between Biofilm Formation and Flagellar Synthesis. Journal of Bacteriology, 193, 2587-2597. http://dx.doi.org/10.1128/JB.01468-10

[22] Wang, X., Preston III, J.F. and Romeo, T. (2004) The pgaABCD Locus of Escherichia coli Promotes the Synthesis of a Polysaccharide Adhesin Required for Biofilm Formation. Journal of Bacteriology, 186, 2724-2734. http://dx.doi.org/10.1128/JB.186.9.2724-2734.2004

[23] Dierksen, K.P. and Trempy, J.E. (1996) Identification of a Second RcsA Protein, a Positive Regulator of Colanic Acid Capsular Polysaccharide Genes, in Escherichia coli. Journal of Bacteriology, 178, 5053-5056.

[24] Henderson, I.R., Meehan, M. and Owen, P. (1997) Antigen 43, a Phase-Variable Bipartite Outer Membrane Protein, Determines Colony Morphology and Autoaggregation in Escherichia coli K-12. FEMS Microbiology Letters, 149, 115-120. http://dx.doi.org/10.1111/j.1574-6968.1997.tb10317.x

[25] Danese, P.L., Pratt, L.A., Dove, S.L. and Kolter, R. (2000) The Outer Membrane Protein, Antigen 43, Mediates Cellto-Cell Interactions within Escherichia coli Biofilms. Molecular Microbiology, 37, 424-432. http://dx.doi.org/10.1046/j.1365-2958.2000.02008.x

[26] Hasman, H., Schembri, M.A. and Klemm, P. (2000) Antigen 43 and Type 1 Fimbriae Determine Colony Morphology of Escherichia coli K-12. Journal of Bacteriology, 182, 1089-1095.

http://dx.doi.org/10.1128/JB.182.4.1089-1095.2000 
[27] Karatan, E. and Watnick, P. (2009) Signals, Regulatory Networks, and Materials That Build and Break Bacterial Biofilms. Microbiology and Molecular Biology Reviews, 73, 310-347. http://dx.doi.org/10.1128/MMBR.00041-08

[28] Botsford, J.L and Harman, J.G. (1992) Cyclic AMP in Prokaryotes. Microbiology Reviews, 56, 100-122.

[29] Jackson, D.W., Simecka, J.W. and Romeo, T. (2002) Catabolite Repression of Escherichia coli Biofilm Formation. Journal of Bacteriology, 184, 3406-3410. http://dx.doi.org/10.1128/JB.184.12.3406-3410.2002

[30] Shimada, T., Fujita, N., Yamamoto, K. and Ishihama, A. (2011) Novel Roles of cAMP Receptor Protein (CRP) in Regulation of Transport and Metabolism of Carbon Sources. PLOS ONE, 6, e20081. http://dx.doi:10.1371/journal.pone.0020081

[31] Korea, C.G., Badouraly, R., Prevost, M.C., Ghigo, J.M. and Beloin, C. (2010) Escherichia coli K-12 Possesses Multiple Cryptic but Functional Chaperone-Usher Fimbriae with Distinct Surface Specificities. Environmental Microbiology, 12, 1957-1977. http://dx.doi.org/10.1111/j.1462-2920.2010.02202.x

[32] Atlung, T. and Ingmer, H. (1997) H-NS: A Modulator of Environmentally Regulated Gene Expression. Molecular Microbiology, 24, 7-17. http://dx.doi.org/10.1046/j.1365-2958.1997.3151679.x

[33] Wurpel, D.J., Beatson, S.A., Totsika, M., Petty, N.K. and Schembri, M.A. (2013) Chaperone-Usher Fimbriae of Escherichia coli. PLoS ONE, 8, e52835. http://dx.doi:10.1371/journal.pone.0052835

[34] Stewart, P.S. and Franklin, M.J. (2008) Physiological Heterogeneity in Biofilms. Nature Reviews in Microbiology, 6, 199-210. http://dx.doi.org/10.1038/nrmicro1838

[35] Wimpenny, J., Manz, W. and Szewzyk, U. (2000) Heterogeneity in Biofilms. FEMS Microbiology Reviews, 24, 661671. http://dx.doi.org/10.1111/j.1574-6976.2000.tb00565.x

[36] Veening, J.W., Smits, W.K. and Kuipers, O.P. (2008) Bistability, Epigenetics, and Bet-Hedging in Bacteria. Annual Reviews of Microbiology, 62, 193-210. http://dx.doi.org/10.1146/annurev.micro.62.081307.163002

[37] Gómez-Gómez, J.M. (2010) Aging in Bacteria, Immortality or Not-A Critical Review. Current Aging Science, 3 , 198-218. http://dx.doi.org/10.2174/1874609811003030198

[38] Claessen, D., Rozen, D.E., Kuipers, O.P., Søgaard-Andersen, L. and van Wezel, G.P. (2014) Bacterial Solutions to Multicellularity: A Tale of Biofilms, Filaments and Fruiting Bodies. Nature Reviews Microbiology, 12, 115-124. http://dx.doi:10.1038/nrmicro3178

[39] Gómez-Gómez, J.M. (2013) Into the Life and Death: RecA a WISE Factor Working to Integrate Survival and Evolution in Escherichia coli. Advances in Bioscience and Biotechnology, 4, 442-449. http://dx.doi.org/10.4236/abb.2013.43A059

[40] Hasman, H., Chakraborty, T. and Klemm, P. (1999) Antigen-43 Mediated Autoaggregation of Escherichia coli Is Blocked by Fimbriation. Journal of Bacteriology, 181, 4834-4841.

[41] Budrene, E.O. and Berg, H.C. (1991) Complex Patterns Formed by Motile Cells of Escherichia coli. Nature, 349, 630633. http://dx.doi.org/10.1038/349630a0

[42] Gabig, M., Herman-Antosiewicz, A., Kwiatkowska. M, Los, M., Thomas, M.S. and Wegrzyn, G. (2002) The Cell Surface Protein Ag43 Facilitates Phage Infection of Escherichia coli in the Presence of Bile Salts and Carbohydrates. Microbiology, 148, 1533-1542.

[43] Zhang, Q. and Yan, T. (2012) Correlation of Intracellular Trehalose Concentration with Desiccation Resistance of Soil Escherichia coli Populations. Applied and Environmental Microbiology, 78, 7407-7413. http://dx.doi.org/10.1128/AEM.01904-12 
Scientific Research Publishing (SCIRP) is one of the largest Open Access journal publishers. It is currently publishing more than 200 open access, online, peer-reviewed journals covering a wide range of academic disciplines. SCIRP serves the worldwide academic communities and contributes to the progress and application of science with its publication.

Other selected journals from SCIRP are listed as below. Submit your manuscript to us via either submit@scirp.org or Online Submission Portal.
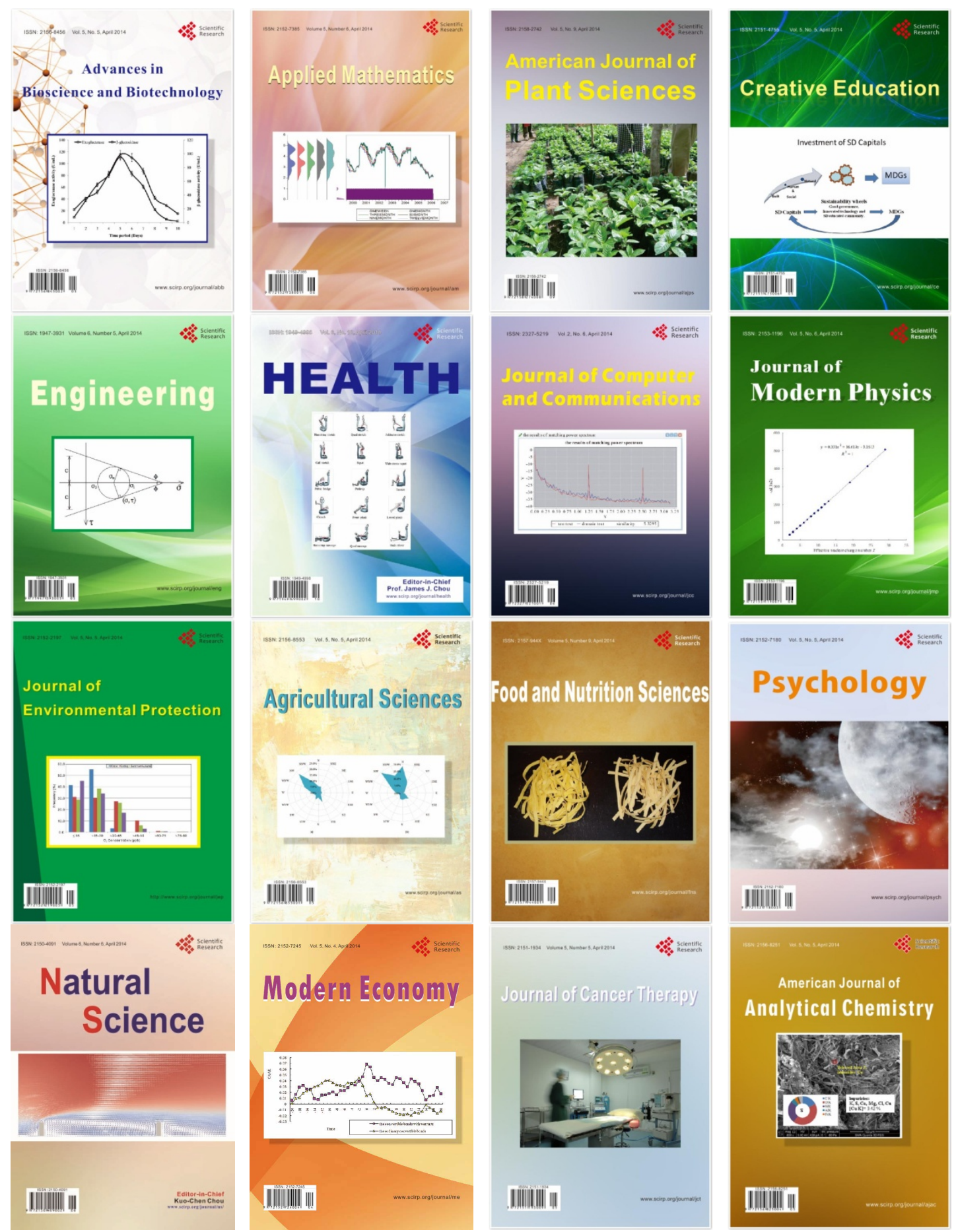